\title{
Multilateral Model Exercise of Sprint on Track and Field for Elementary School
}

\author{
$1^{\text {st }}$ Ika Novitaria \\ Coaching Sport Education \\ Faculty of Sport Science \\ Jakarta State University \\ Jakarta, Indonesia \\ ikanovi1979@gmail.com
}

\author{
$2^{\text {nd }}$ Moch. Asmawi \\ Professor of Postgraduates \\ Study Program \\ Jakarta State University \\ Jakarta, Indonesia
}

\author{
$3^{\text {rd }}$ Rizky Nurulfa \\ Degree College Student of \\ Postgraduates Study Program \\ Jakarta State University
}

\begin{abstract}
The learning orientation should be tailored to the child's development, content and material affairs as well as the way the delivery should be tailored so as to be interesting and fun. The aim of this research is to develop a multilateral model exercise of the sprint on track and field and to find how effective the model of multilateral model exercise that has been made. This research was using a research and development method. The result of this research is: developing 25 exercise of the sprint on track and field based on multilateral and the model was effective to increase the result of sprint for elementary school age.
\end{abstract}

\section{Keywords-Multilateral Model, exercise of sprint, elementary school, track and field}

\section{INTRODUCTION}

Doing physical activity is very important in a child's development, with regular exercise can support the child's ability to concentrate on other subjects in school. This was stated by Bailey, Richard., Armour, Kathleen said that physical education has a role in the acquisition and development of children 's movement skills and physical competence[1]. Beside that physical activity also can improve children's concentration and arousal, which might indirectly benefit academic performance. Based on these results, the school should develop sports activities regularly and continuously. Sports activities conducted not only in the learning activities but also in activities outside of school hours such as extracurricular activities. It is as disclosed in a study conducted by Fischetti Francesco, Gianpiero Greco, which showed that: an extracurricular of physical activity performed using a multilateral approach might be more beneficial than having only standard programs at the school[2].

However, in reality, the school only performs activities of physical activity in the learning of physical education once a week. So, the children have limitations of time to do physical activity. Limitations of time in physical education lessons will encourage children to increase physical activity either through additional personal training programs or follow extracurricular in school. Because the ultimate goal of doing sports is to reach achievement in a competition. But the competition for children is different from adult athletes because the competition for children has aims to stimulate the children to perform a skill. Therefore, a coach needs a knowledge of how children grow and develop. The form of the game is a major part of the learning of motion in elementary school. To make learning interesting, the trainer must make a fun learning design so that students can develop the confidence and competence they have. It is stated by Virgilio, Stephen that "Young children are naturally active [3]. They love to play and express themselves through movement. Take advantage of this to promote fitness fun. Keep in mind that if children think an activity is fun and enjoyable, they will repeat it over and over again".

Based on the explanation above, it appears that there have been several studies related to the learning to improve the sport movement mainly elementary school children. However, not many people doing research on a model-based multilateral exercises to improve the ability to run fast on elementary school children. The concept of the development model created by the researchers is a model-based multilateral exercises which contain basic movement exercises run combined with the basic movements, jumping, throwing, catching, balancing, and so on. Multilateral notion advanced by Lubis[4] as the overall physical development.

Through this development of a child can perform natural movements such as speed, flexibility, agility, coordination and overall aspects of fitness in general. Multilateral development is important for children to develop basic skills that can help children become athletes in sports practice. This is supported by research conducted by Bruno Magnani, Manuel Rizzardini would be sufficient to improve motor skills in primary school children, although some neuromotor abilities could be improved through more specific exercises without creating particular damage"[5]. Bompa, Tudor believes that the exercise for general physical development lays the groundwork for further training by improving the quality of basic motion which is a major component of the multilateral program[6]. Thus it can be concluded that the multilateral exercise program is the 
basic foundation of general physical development training so it must be given to the child.

Athletics is the mother of all sports and can improve the physical quality of the students so that more fit, it is not uncommon athletic become a tedious activity. Especially the running number. Running is a physical activity and basic motion needs to be tailored to the child's development. Thus, the coach must perform a wide variety of models running exercises combined into motion diverse (multilateral) or a game packed with interesting tools so that children are challenged to follow a practice run in accordance with the character's age and physical abilities of the child.

A short distance run number is a number that requires maximum strength and speed from the start line to the finish line. According to Dunville, Ben Lioyd Howey dan Ron Parker that: "sprinting is beginning in a stationary position, the objective of sprinting is to move from the starting position to the finish line as quickly as possible"[7].

Based on the explanation above, the purpose of this study was to develop a model based multilateral athletic training and adjustment to adopt a number of competition in an athletic contest for children called athletic kids but focus on running numbers. Additionally, to see the effectiveness of this type of training that has been made.

\section{MATERIALS AND METHODS}

The purpose of this research is: to develop a model based multilateral sprinting exercises for primary school children and to determine the effectiveness of improvement after being given quick run-based multilateral exercises that have been developed. The method used in this research is research and development. This methodology research suggest [8] research and development is an industry-based development model in which the findings of the research are used to design new products and procedures, which are then systematically fieldtested, evaluated, and refined until they meet the specified criteria of effectiveness, quality or similar standards. This design was chosen to be used in clear stages.

The stages of research and methodology of Borg and Gall is illustrated in this image below:

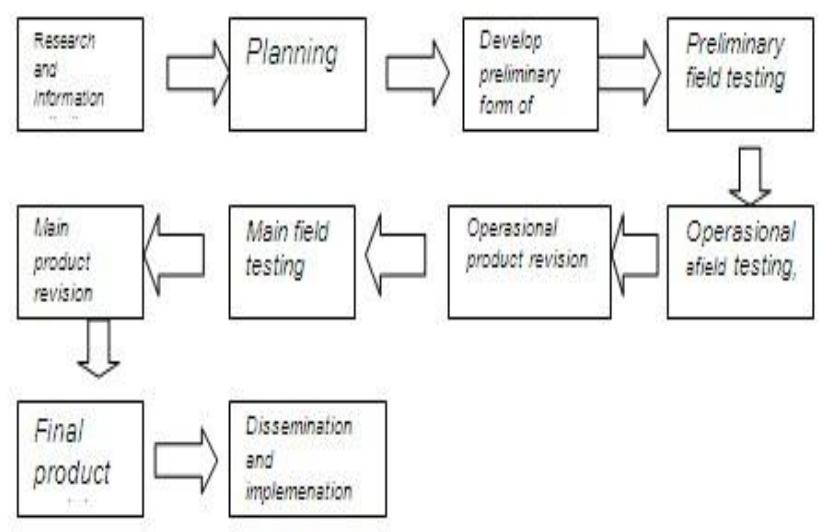

Fig. 1 Research and Methodology of Borg and Gall

\section{RESULTS AND DISCUSSION}

The results of this study can be seen based on the stages of the research and development that is used in this study are:

1. Preliminary research results. To find out the problems and the need for the problems examined, it is necessary to conduct a needs analysis with observation and interviews with athletes and athletic trainers. Observations found in the field, that if children do exercises run fast without using tools that are interesting or fast running drills without variation of motion then the child will feel tired and do not do the instructions given by the coach. In addition, it was also found that the majority of children liked running exercises packed with obstacles in groups using various training mediums.

2. Planning and model development. After analyzing the needs of the issues examined, the next is the planning and development of this type of training sprint is a model-based multilateral exercise. At this stage, the product came to be designed based on information about the problems and needs that run the basic motion problem fast for elementary school children. Products developed referring to the purpose of research is a model for fast run-based multilateral by adjusting the characteristics of elementary school children.

3. Validation, evaluation, and revision of the model. Before the development of a fast-running practice model was tested, the experts validated the developed multilateral fasttrack practice model. Experts validate the exercise model based on the basic characteristics and motion required by elementary school children and athletic branches of fasttrack numbers. Expert validation results say that the multilateral-based fast-track practice model is worth using. In addition to validation, experts also evaluate the design of the model made. Evaluations made by related experts on naming the exercise model, the distance between the tools used, the safety level of the students and considering the multilateral basic motion elements adapted to primary school children. After receiving inputs and suggestions from experts, a draft improvement of the draft model was developed to be used as a reference for product improvement prior to field trial. After obtaining validation, evaluation, and revision of the model, a small group trial was conducted by giving 25 models to Singapore International School Pantai Indah Kapuk West Jakarta.

4. Test for the effectiveness of the model. To examine the effectiveness of exercise models developed to increase the results of a quick run, the administration of the modelbased multilateral sprinting exercises that have been revised. To get the effectiveness of the model, the test was taken before and after the treatment of the modeling of running practice was done. The test was a quick run test of 40 meters. Based on the results of the initial test and final test, the value of $t_{\text {count }}=7.79$ and $t_{\text {table }}=1.70$ at the 0.05 significance level. Therefore $t_{\text {count }}$ is bigger than $t_{\text {table }}$, hence it can be concluded that multilateral fast-run training effectively improve the ability to run fast in elementary school age children. 
Based on the results of the above research, it can be seen that there is a comparison of the results of a quick run before the applied model run quickly developed after the applied. Preliminary test results before applying the average fastrunning practice model are 11.40 seconds. With the lowest record time is 17.54 seconds and the fastest time is 9.09 seconds. Meanwhile, after the implementation of the model of fast-running practice, the average time is 10.33 seconds. With the lowest time record is 16.87 seconds and the fastest time is 7.06 seconds. The development of this exercise model is based on an athletic competition created by IAAF for children called Kids Athletic. But the exercises are still less attractive, less varied and do not pay attention to the problem of growing children, so the exercise is felt very monotonous and boring. Whereas at the age of children, it takes a practice that leads to a multilateral motion. As the study by Ngadiman, which states that: "kid's athletics is considered as the athletic basic movement of experiences, athletics is more to the childhood of the early ages, and the implementation of multilateral development models"[9].

This is also supported by research conducted by Oleksandr Krasilshchikov which states that: "Multilateral training is often considered as a solution for overall development of young athletes[10]. Besides the obvious health-related benefits, physical activities help to unfold natural development potential in children. They get used to exploit their motor abilities in variable situations and intensities". As for some advantages of this product include:

1. Increased courage and running ability.

2. Present a game that fits the child's characteristics and child's motion skills, thereby increasing the child's motivation for athletic training, especially running numbers.

3. Students become more active, and enthusiastic in athletic learning with the use of simple and attractive training tools for children.

Based on the results of the above inputs can be concluded that the use of facilities and infrastructure is considered good for use in the training process because it is a tool that is safe for children. Children can be stimulated to move by using interesting tools, in which case the trainer can modify the tool according to the school conditions and student needs. Forms that are arranged in a creative exercise in accordance with the characteristics and needs of the child motion can increase the child's motivation in practice. Variations diverse movement by using multilateral principles can improve basic motor skills of children, especially in this case the ability to run fast. In addition, the coach can also modify the rules of the game to adjust the characteristics of the students, so that the process can run properly exercise and fun.

\section{CONCLUSION}

The results showed that there are 25 models of running drills quickly developed a model based on multilateral and is effective for improving the results of a quick run on elementary school children. This model is expected to be a reference and provide ideas for trainers to train the sprint for children elementary school children. Because of all this, this type of training given by trainers does not conform with the development of the child. The model was developed using a variety of basic movements and variations in the use of a simple and attractive so that exercise becomes attractive and can increase the child's motivation to practice.

\section{REFERENCES}

[1] Bailey, Richard., Armour, Kathleen., etc, 2009, The Educational Benefits claimed for Physical Education and School sport: An Academic Review, Research papers in Education, 24: 1 - 27.

[2] Fischetti Francesco, Gianpiero Greco, Multilateral methods in Physical Education improve physical capacity and motor skills performance of the youth, Journal of Physical Education and Sport, 2017, Supplement issue 4, Art 223, pp.2160 - 2168.

[3] Virgilio, Stephen J. 2012. Fitness Education for Children. United State of America : Human Kinetic.

[4] Lubis, Johansyah. 2013. A Practical Guide For Preparing The Exercise Program. Jakarta : Kharisma Putra Utama.

Bruno Magnani, Manuel Rizzardini, dkk, Evaluation of The Effects Of Specific Karate Exercises During Multilateral Training In Children Of Primary School, Italian Journal Of Anatomy And Embryology, 2015, vol. $120 ; 208$.

[6] Bompa, Tudor O. Periodization Theory and Methodology of Training. United States of America: Human Kinetics, 2009.

[7] Dunville, Ben Lioyd Howey dan Ron Parker. 2006. Run Jump Throw. Canada : Athletics Canada.

[8] Richey dan Klein. 2011 Design and Development Research. London: Lawrence Erlbaum Associates.

[9] Ngadiman, The Evaluation of Kids Athletic Massing Program, IOP Conf. Series: Materials Science and Engineering 180 (2017) 012174.

[10] Oleksandr Krasilshchikov, Effects Of Short Term Multilateral And Sport Specific Training On Physical Fitness Profile Of Malaysian School Children, International Journal of Research Pedagogy And Technology In Education And Movement Sciences (Ijems), 2013, 1: $30-42$ 